\title{
Research on the Influence of SMEs' Enterprise Incentive System on Employees' Performance--A Case Study on HBhaoLinJu Trading Co., Ltd
}

\author{
Yuxi Zhang \\ The Faculty of Management, China Women's University, China.
}

1317685240@qq.com

Keywords: Private enterprise, incentive theory, enterprise incentive system.

\begin{abstract}
With the further intensification of market economy, the competition in various enterprises is accordingly increased. For them, the core of competition is how to win the talents in essence. Small and Medium Enterprises (SMEs) have now become the new growth point which is most dynamic in Chinese socialist market economy. And they have played an important role in technological innovation and offering more job opportunities. In order to straighten their productivity and competitive capacity, these SMEs will apply some incentives to maximize employees' commitment, enhancing employees' loyalty to the company. This paper firstly studies the relationship between the enterprise incentive system in certain enterprise and its employee performance. The influence of enterprise incentive system on the employees' performance is then specialized on. Against these, some systematic and scientific measures are finally proposed to solve the pertinent problems in the enterprise incentive system.
\end{abstract}

\section{Introduction}

The Chinese economy promotes the establishment and development of various SMEs. And the socialist market economy is the cradle of the enterprises. The SMEs have become the new growth points in Chinese socialist market economy in which the retail industry develops rapidly. Supermarkets can be seen everywhere on the streets today. However, with the in-depth development process, factors that do not adapt to it gradually become more and more prominent. One of these most important factors is that SMEs lack an enterprise incentive system that can attract their employees, mobilize employees' enthusiasm, and maintain employees' loyalty to them.

This study takes the HBhaoLinJu retail supermarket Co., Ltd as an example. In this article, the writer tries to analyze and research the establishment and improvement of enterprise incentive system of certain enterprise. Some theoretical guidance for human resource department can be come up with, as the establishment and improvement of the enterprise incentive system is one of the most important tasks of the human resource department. Finally, the enterprise incentive system is an important means for the company to improve their employee performance, so this research will help it straighten employee performance. First, the relevant issues that occur in the incentive mechanism are collected and researched the enterprise incentive systems, this study can help companies avoid or reduce such problems or issues when they practice enterprise incentive systems in the companies. Secondly, this thesis now studies the problems and flaws of the enterprise incentive system. At the same time it proposes some solutions and improvement measures. The companies can learn from the experience and improve the level of management in practice, which is conducive to their development. Finally, the thesis will help various establish scientific management system and straighten core competitiveness.

\section{Literature Review}

Since the reform and opening up in China in 1980s, the theory of human resource management has been increasingly mature in practice. It is widely accepted by enterprises and gradually replaces personnel management in the enterprises. In the 1990s, this theory continues to develop. With the reform and opening up in China, human resources management has gradually been accepted and 
applied by domestic enterprises. In particular, in order to straighten the core competition, some SMEs took some enterprise incentive systems to further enhance employees' commitment, maintain loyalty, achieve their strategic goals and promote productivity. In this article the comprehensive review of domestic and foreign research results is demonstrated including the definition of the enterprise incentive system, the role of incentive system, the definition of the employees' working performance, and the relationship between the enterprise incentive system and employees' performance.

\subsection{Definition of Enterprise Incentive System.}

Based on the definition in the research conducted by previous scholars, the definition of enterprise incentive system can be summed up as a kind of human resource management method in which the incentive subject shares a common future with the incentive object and constrain each other to maximize the value of the incentive object through various incentive measures as long as the enterprise incentive mechanism is established. The modern enterprise incentive system mainly includes the external and internal enterprise incentive systems. They are listed as follows. The external enterprise incentive system mainly refers to the incentive subjects outside the enterprises such as the government, consumers, and the public. Internal enterprises incentives mainly refer to the incentives inside the enterprises such as managers and the chairman. (Xu Wenham 2014)

Motivator's theory: Motivators are various reward resources used by the companies to mobilize the enthusiasm of employees. The extraction of inducing factors must be based on personal needs of the team member through investigation, analysis, and prediction of the enterprises. And according to reward resources the organization has at that time, reward forms are designed, which includes external and internal rewards. Hierarchy of needs theory can be used to guide the extraction of motivators. (Peng 2014).

The motivation mechanism is a set of rationalized systems to reflect the way in which the incentive subject interacts with the object. In his book how to Motivate Employees, Dr. M. Leboeuf points out that greatest principle in the world is reward; people will perform better if they are rewarded. The motivation mechanism includes the following five aspects: (1) motivators collection system; (2) behavior-oriented system; (3) behavioral scale system; (4) behavioral space-time system; (5) behavioral assimilation system. The five aspects compose the motivate mechanism in which the motivators induce and guide behavior, and the others guide, regulate, and restrict the behavior. The five factors interact with each other to allow the motivation mechanism to play a full role. (Li Libya \&Wang Shooing 2008).

\subsection{The Role of Incentives.}

Jibe Ying summarized in her article that the motivation mechanism act on internal organization, leaving the organization in a certain state, and further influencing the survival and development of the organization as long as the incentive mechanism is established. The motivation mechanism has duel effects and two roles, that is to say, it can encourage and induce the organization. At the same time, it can also weaken and undermine the organization. (1) In one aspect, certain motivation mechanism can repeatedly strengthen and improve the behavior of the employees that could meet the organization's expectations. Under such a motivation mechanism, the organization continues to develop. Such motivation system has the encouraging role. (2) On the other aspect, due to the anti-motivation factors in the motivation system, the expected behavior of employees does not show up. The original intention of the incentive mechanism is to mobilize the enthusiasm of employees and achieve the goals of the organization through its enterprise incentive system. However, if the enterprise incentive system is not comprehensive or it is not feasible in practice, it will inhibit or weaken the enthusiasm and creativity of some employees. This is the weakening effect of the incentive mechanism. (Jibe Ying 2008).

\subsection{Incentive Theory.}

In McClelland's “achievement need theory”, he divided job-related need into achievements, friendships, and power. The first two equaled to Maslow's self-realization and social need, while the latter referred to the desire to influence and control others. He pointed out the close relationship between achievement need and job performance. And a series of methods of stimulating achievement 
needs of some employees were proposed by him. At the same time, he presented that friendship and power needs closely related with the managers' success.

Hertzberg's "two-factor theory" pointed out that hygiene factor which was composed of some elements and working conditions and situation can merely eliminate employees' dissatisfaction, but they cannot stimulate employees' working enthusiasm. The other factors and working contents composed motivator factor which can stimulate employees' enthusiasm.

Furlong's "expectation theory" believed that there were three important variables that could determine the level of motivation: 1. Expected value (E). It was the subjective probability of achieving desired performance of the organization through certain motivation methods which would push people hard toward the selected goals; 2. Instrumental value (I). It was the chance of obtaining the reward after achieving the desired performance level. That is to say, it was a kind of success probity estimated by individuals. 3. Valence price (V). It referred to the relative value of different rewards in the mind of the personal parties. The enthusiasm (incentive intensity) to obtain targeted reward is determined by these variables factors.

Adams' "equity theory" thought that employees' satisfaction was not absolute values. Their satisfaction was different in different society and historical period. So it depends. It was a series of comparative value. People would like to compare themselves with others who have similar conditions. If their ratio is equal, they would fell fair and satisfied;

Robert House's "comprehensive incentive model theory" integrated various incentive theories through certain model, which emphasized the internal role of the task itself and external rewards resulted from other tasks. Some people researched how to meet people's needs. Some researches focused on motives and the psychological process while others studied the purpose of incentives.

\subsection{Performance Assessment.}

Shao Lily (2011) believed that performance assessment mainly referred to the process of collecting, analyzing, and feeding back employees' working performance and results based on the standards. The performance assessment had three characteristics: (1) it depended on multiple factors, (2) it could analyze and evaluate employees’ performance from multiple angles and perspectives; (3) it would be different from the assessment in the past. The main content of performance assessment is to evaluate employees' working efficiency and working results, professional ability, ideological attitude, political performance, moral and psychological performance, and working attitude.

Wang Xiao Hua believed that performance assessment is a motivation means of personal management. For the enterprises, performance assessment can determine employee recruitment, job elevation, training opportunities and development, and wages and wages to fully utilize the enterprise motivation mechanism, which is conducive to the healthy development of the company. For employees, performance assessment helped them establish the positive mental model.

\section{Methodology}

This paper takes survey method. First, according to the company's current business stage, an interview outline is designed, and the enterprise incentive system to employees is determined by interviewing some executives of human resources department. Second, a questionnaire is constructed to measure the employees' evaluation to the enterprise. A set of scales is designed to demonstrate employees' degree of satisfaction and preference for the enterprise incentive system.

\section{Enterprise Profile}

Established in January 2001, HBhaoLinJu Trading Co., Ltd. is a key project invested by the government of Jinzhou, Hubei province. With the registered capital of CNY10 million, the enterprise is led by the forwarding-looking executives with advanced management experience and specializes in supermarket business. After ten years of steady development, the enterprise scale will continue to develop. 
In recent years, the company has developed rapidly. It takes advantage of low-cost, superior commercial outlets, and advanced supermarket management concepts. With the enterprise aim of "Good neighbors for everyone", it meets consumer's need to provide excellent and cheap products and high-quality services. It leads an innovative and excellent team that continuously makes progress working in a healthy development track.

\section{Finding and Result}

\subsection{Demographic Description.}

Basic sample information

Table 1. sample basic information

\begin{tabular}{cccc}
\hline & & number & percentage N \% \\
\hline \multirow{2}{*}{ Gender } & Male & 9 & $30 \%$ \\
& Female & 21 & $70 \%$ \\
\hline \multirow{4}{*}{ Age } & $18-25$ & 6 & $20 \%$ \\
& $25-35$ & 9 & $30 \%$ \\
& $35-45$ & 10 & $36.67 \%$ \\
& $45-55$ & 4 & $10 \%$ \\
\multirow{3}{*}{ Monthly income } & Over 55 & 1 & $3.33 \%$ \\
& Less than 5000 & 8 & $26.67 \%$ \\
& $5000-7500$ & 15 & $50 \%$ \\
& $7500-10000$ & 3 & $10 \%$ \\
\multirow{3}{*}{ Position } & Over 10000 & 4 & $13.33 \%$ \\
& Senior Management & 1 & $3.3 \%$ \\
& Middle management & 4 & $13.3 \%$ \\
& Technical staff & 5 & $16.7 \%$ \\
& Salesmen & 12 & $40.0 \%$ \\
& Other position & 8 & $26.7 \%$ \\
\hline
\end{tabular}

(1) Gender: the sample size is 30 that include 9 males, accounting for $30 \%$ in total, and 29 females, accounting for $70 \%$.

(2) Age: The age spans from 18 to over 55. The respondents between 35 and 45, account for $36.67 \%$; the respondents between 18-25 years old, account for 20\%; the respondents between 25-35 years old, account for 30\%; the respondents between $45-55$ years old, account for $10 \%$; the respondents over 55 years, account for $3.33 \%$.

(3) Monthly income: 8 people with less than CNY5, 000, accounting for 26.67\%; 15 with 5, 000-7, 500 , accounting for $50 \%$; 3 with $7,500-10$, 000 , accounting for $10 \%$; 4 with more than 10,000 , accounting for $13.33 \%$.

(4) Position distribution: 1 senior management, accounting for 3.3\%; 4 middle management, accounting for 13.33\%; 5 technical staff, accounting for 16.7\%; 12 salesmen, accounting for $40 \%$; the other is 8 , accounting for $26.7 \%$.

\subsection{Average Analysis.}

Table 2. Average analysis

\begin{tabular}{ccc}
\hline & average & $\mathrm{N}$ \\
\hline Evaluation of remuneration incentive & 2.80 & 30 \\
Relevance of wages and benefits & 2.03 & 30 \\
sense of achievement & 2.50 & 30 \\
Communication and incentive from leaders & 2.00 & 30 \\
Company culture and sense of belonging & 2.40 & 30 \\
career development and treatment & 2.57 & 30 \\
Material and Spiritual Incentives & 2.00 & 30 \\
\hline
\end{tabular}

Assign the options to these questions in the questionnaire: 1 means pretty approved; 2 approved; 3 moderate; 4 less acceptable; 5 unacceptable. (1) The employees' evaluation to enterprise incentive evaluation is 2.80. It is within the approved and average range. (2) Employees believe that the salary 
growth positively is correlated with the company's benefits and the assignment value is 2.03. (3) The assignment value of employees' sense of satisfaction is 2.5 and it is between approved and average. (4) The average value Communication and incentive from leaders is 2.00 , and is approved. (5) The average value of company culture and sense of belonging 2.4. The assignment is between approval and average. (6) The assignment of career development and treatment is 2.57and is between the approval and average, tending to be average. (5) The average value of material and spiritual Incentives is 2.00, and is approved.

\subsection{Frequency Analysis of Preferences.}

Table 3. The most concerned elements in the working

\begin{tabular}{cccccc}
\hline & Frequency & Percentage & Effective Percentage & Cumulative Percentage \\
\hline \multirow{4}{*}{ elements } & Sense of identity & 4 & 13.3 & 13.3 & 13.3 \\
& Salary & 13 & 43.3 & 43.3 & 56.7 \\
& self-value & 8 & 26.7 & 26.7 & 83.3 \\
& prospect & 5 & 16.7 & 16.7 & 100.0 \\
& Total & 30 & 100.0 & 100.0 & \\
\hline
\end{tabular}

Table 4. Multiple-choice frequency analysis of motivation factors by employees

\begin{tabular}{c|c|c|c}
\hline & \multicolumn{2}{|c|}{ Response } & \multirow{2}{*}{ Percentage in cases } \\
\cline { 2 - 3 } & $\mathrm{N}$ & Percentage & $100.0 \%$ \\
Remuneration & 26 & $10.8 \%$ & $92.3 \%$ \\
Promotion opportunity & 24 & $10.0 \%$ & $92.3 \%$ \\
Training opportunity & 24 & $10.0 \%$ & $84.6 \%$ \\
Welfare & 22 & $9.2 \%$ & $50.0 \%$ \\
Management participation & 13 & $5.4 \%$ & $96.2 \%$ \\
Working environment & 25 & $10.4 \%$ & $88.5 \%$ \\
Trust from leaders and colleagues & 23 & $9.6 \%$ & $53.8 \%$ \\
Challenges of work & 14 & $5.8 \%$ & $84.6 \%$ \\
Good corporate culture & 22 & $9.2 \%$ & $88.5 \%$ \\
Fair distribution & 23 & $9.6 \%$ & $923.1 \%$ \\
Total & 240 & $100.0 \%$ & \\
\hline
\end{tabular}

Frequency analysis: 13 employees choose salary and wages as the most concerned elements in the working. It had the highest frequency, accounting for $43.3 \%$. And the frequency of sense of identity, self-value, and prospect was 4,8 , and 5 respectively. The highest rate of motivation factors was remuneration, with a frequency of 26; followed by working environment with a frequency of 25.

\subsection{Chi-square Test.}

Table 5. Salary incentive evaluation

\begin{tabular}{cccc}
\hline & Observed number & Expected number & Residual number \\
\hline Very strong & 2 & 6.0 & -4.0 \\
Strong & 14 & 6.0 & 8.0 \\
Not clear & 5 & 6.0 & -1.0 \\
Not enough & 6 & 6.0 & .0 \\
Bad & 3 & 6.0 & -3.0 \\
Total & 30 & & \\
\hline
\end{tabular}

Table 6. Communication and incentive from leaders

\begin{tabular}{cccc}
\hline & Observed number & Expected number & Residual number \\
\hline Very useful & 13 & 7.5 & 5.5 \\
useful & 12 & 7.5 & 4.5 \\
average & 2 & 7.5 & -5.5 \\
useless & 3 & 7.5 & -4.5 \\
\hline Total & 30 & & \\
\hline
\end{tabular}


Table 7. Test statistics.

\begin{tabular}{ccc}
\hline & Wages incentive evaluation & Communication and incentive from leaders \\
\hline chi-square & $15.000 \mathrm{a}$ & $13.467 \mathrm{~b}$ \\
do & 4 & 3 \\
p-value & .005 & .004 \\
\hline
\end{tabular}

Chi-square test analysis: The chi-square value of salary incentive was 15.000; the degree of freedom was 4 . The $\mathrm{P}$ value was 0.005 , and significant at $5 \%$; the motivation and incentive from leaders was 13.467 , the degree of freedom is 3 . The $\mathrm{P}$ value was 0.004 and lower 0.005 , so it was significant at the $5 \%$.

5.5 Single Factor Chi-square Test.

Table 8. Effects of Different Ages on Material Incentives and Spiritual Incentives

\begin{tabular}{ccccc}
\hline Age & $\mathrm{n}$ & axis & $\mathrm{F}$ & $\mathrm{p}$ \\
\hline $18-35$ & 15 & $1.73 \pm 0.458$ & 11.200 & .002 \\
$35-55$ & 15 & $1.20 \pm 0.414$ & 11.20 & \\
\hline
\end{tabular}

Single factor chi-square test: the material incentive value was assigned 1, and the spiritual motivation 2. $\mathrm{P}=0.02<0.05$ meant that there was a significant difference between the two groups, so it could prove that people of different age had different reaction to incentives.

\section{Current Situation of Enterprise Incentive System of HBhaoLinJu}

At present, the main incentives forms in this company involved compensation, target incentives, training opportunity and honor. The company used remuneration and welfare as the key incentives methods, which were linked to employee performance. It reflected the importance of the employees' position, the level of responsibility, and the working difficulty. To a certain extent, the enterprise incentive system was conducive to straightening the enthusiasm, initiative and creativity of the employees in this enterprise.

\section{Existing Problems in the Enterprise Incentive System}

\subsection{The Enterprise Incentive System Is Not Fully Suitable for the Current Circumstance of The Company.}

Human resources management has gradually been accepted and applied by domestic enterprises, since China reformed and opened up. The company's enterprise incentive system has developed late. In its early stage, it did not attach importance to the enterprise incentive system, resulting in low employee motivation, weak creativity and slow operation. Later, internal adjustments were made, but it directly referenced the enterprise incentive system from a more advanced company that was not suitable because they lack relevant experience. The different operation stage, quality and quantity of personnel and scale would affect the establishment of enterprise incentive system. There is still a certain gap between the company and industry benchmarking companies. If an enterprise incentive system that is suitable for the company's current operation stage, it will have a certain negative impact on employees' performance and weaken their enthusiasm.

\subsection{Inappropriate Compensation Led to Ineffective Employment Mechanism.}

In this survey, the employees' attitude towards their salary level was measured. The average value was 2.80, and it was in a modest level. So it can be concluded that employees are not satisfied with the salary system. If the remuneration system that was designed by the company is unreasonable and fails to meet the needs of employees, it will cause some problems in the employment mechanism and may lead to unfair phenomena and injustice act. The result is that those who work harder cannot receive the appropriate compensation and those who do less work get the same salary. Besides, it may also lead to united enterprise culture where employees' enthusiasm and performance is declining and the enterprise is not united anymore. The company merely keeps employees through internal trust. In the 
long term, employees will be disappointed with the company. The company may lose the trust of the company employees and finally they will leave.

\subsection{Enterprise Incentive System is Relatively Single.}

The main incentive forms of HBHAOLINJU are salary and bonus incentives, and the enterprise incentive system is relatively single. With salary incentives and bonus incentives as the main form, the labor costs put great pressure on the economy of the company. In addition, salary and bonus incentives are often linked to performance assessment of the employees. Some problems will occur in the implementation process of the assessment plan. For example, the assessment plan directly weakens the incentives. For the young employees, in addition to salary and bonuses, they also want the company to provide a platform for them to express personality. However, the current enterprise incentive system is not complete and not scientific, so some young employees will leave when they cannot achieve their ambitions in this company. The turnover rate of young employees continues to increase.

\section{Managerial Recommendation}

\subsection{To Develop the Appropriate Enterprise Incentive System based on Development Strategy of the Company.}

The enterprises should sort out its development strategy. And in this the key processes of strategic communication, some improvement measure would be came up with. Strategic decision-making and discussion is a set of TMT consensus in essence, an incentive-based management system should be established. The enterprise incentive system must be based on the development goals of the HBhaoLinJu Trading Co., Ltd and complies with the development strategy thus integrating the targets of employees' with the targets of the enterprise. And the enterprise incentive system must be suitable for the conditions of the company. Only in this way can the enterprise incentive system play a key role in improving employees' enthusiasm, creativity and performance. What's more, united enterprise culture can be established. The employees of this company can feel at home and be more loyal to their home

\subsection{Standardize Remuneration and Employee Performance Assessment System.}

In the early stage, the company took a result-oriented compensation strategy. But it should adopt humanitarian management as well as the behavior-oriented incentive strategy. It should adopt long-term incentive policies to tie its interests with employees' interests. For example, equity incentive methods such as the partnership system can be adopted. For employee performance is linked to employee salaries and bonus incentives, so it requires fairness. It is necessary to strengthen training to improve the quality of employees. Meanwhile the system of performance assessment that is reasonable and accepted by employees to further enhance employees' trust and loyalty to the company.

\subsection{To Increase Encourage Forms and Means of Incentives and Improve the Enterprise Incentive Systems.}

The HBhaoLinJu should take both material and spiritual incentives into the motivation form. Material incentive guarantees the benefits of the corporate and the spirit incentive protects precious and key corporate culture. The company can choose incentives that combine employees' goals with corporate goals. That is to say the targets of employees and the company should be the same one. For example, the incentive for training and development opportunities could urge employees to promote their quality and skills. And corporate cohesion can be enhanced through the method of honorary incentives. The company also can integrate all forms of incentive system to establish a complete and scientific enterprise incentive system that can avoid the shortcomings and negative effects of some incentives.

\subsection{Enterprise Incentive System should be More Targeted to Meet Employees’ Needs.}

In this survey, it was found that with income and position as experimental constants, employees' age and gender were significantly related to the choice of material incentives and spiritual incentives at the 0.01 level. Simply, that is to say, some employees with different ages and genders may choose 
different material incentives and spiritual incentives. For example, the employees of twenties and thirties wished their company to provide them with the opportunity and platform to development in this company. Married women hope to stile a balance between their family and domestic work, so they wanted a stable and nice job and the elderly employees hoped that they can be guaranteed while the level of income will be stable. The company should deeply survey the employees' preferences to establish the enterprise incentive system, which could not only reduce labor costs but also achieve the expected incentive result.

\section{Conclusion}

Today, talents are the productivity of enterprises. And they are also the core of competition between various competitions in this society. Hubei HBhaoLinJu Trading Co., Ltd. should formulate and establish a scientific, standardized, diversified and effective enterprise incentive system based on the company's development strategy at the this period. The enterprise incentive system should meet the diverse need of all employees, through which the skills and performance of the employees can be improved and straightened. In such a way employees' interests are linked to the company's interest. Their sense of belonging and loyalty to the company is enhanced and improved. At the same time, the enterprise culture could be more united. In brief, a comprehensive enterprise incentive system including all of these elements will promote the development of Hubei HBhaoLinJu Co., Ltd.

\section{References}

[1]. Wenham Xu. A Research on enterprise incentive system in Modern Enterprises [J]. Oriental Enterprise Culture, 2014(3):247-247.

[2]. Zhuhai Sun \& Daylong Wang. The Way of Continuous Development of Enterprises - On the enterprise incentive system of human resource management [J]. Manager' Journal, 2013(22):7-10.

[3]. Xianghuai Chen. The Role of Incentive Mechanism in Modern Enterprises [J]. Market modernization magazine, 2008(34):125-125.

[4]. Hong hang Fu. An Analysis of the Incentive Mechanism of Employees of the State-owned Enterprises in China [J]. Market modernization magazine, 2005(29): 250-251.

[5]. Ni Wang, Songhua Zhu, Xinhua Wang, Li Wen. Literature Review of Transformational Leadership Behavior and Employee Performance at Home and Abroad [J]. Business economy, 2013(15):64-65.

[6]. Zhenjiang Qi. An Analysis of Human Resources Portfolio Strategy and its Multi-level Effect under the Entrepreneurial Situation [D]. Zhejiang University, 2007.

[7]. Hailing Gao. A Research on the Construction of Enterprise Salary enterprise incentive system [J]. Forecasting, 2000(1):14-16.

[8]. Yan Zhao. A Research on the Construction of Enterprise Salary enterprise incentive system [J]. China Journal of Commerce, 2014(32):69-71.

[9]. Rung Wang. A Research on the Incentive Mechanism of SCYD Innovation Team [D]. University of Electronic Science and Technology, 2009.

[10]. Ying Jibe. An Analysis of the Ternary Construction of University Science Park [D]. Northeastern University, 2012.

[11]. Xiujuan Zhou. A Research on Human Resources Management Strategy of Daqing Oilfield Company [D]. Northeast Petroleum University, 2011. 
[12]. HI Yang. Excavation and Use of Incentive Resources [J]. East China Economic Management, 2000(5):98-99.

[13]. B.M. Scherer, "Management Psychology," Nunki University Press, 1988.

[14]. Lily Shao. Status Quo of Enterprise Human Resource Performance Assessment and Analysis of Effective Measures [J]. Coal, 2011, 02

[15]. Xiao Hua Wang. Performance assessment method and its application [J]. Enterprise Reform and Management, 2008, 11:69-70. 